\title{
URINARY TRACT INFECTION IN PREGNANCY
}

\author{
Alka Mukherjee ${ }^{1}$, Apurva Mukherjee ${ }^{2}$
}

${ }_{1}^{1}$ MBBS DGO FICMCH RCOG Associate, Department of Obstetrics and Gynaecology, Mukherjee Multispecialty Hospital, Nagpur, Maharashtra, India.

2MBBS, Department of Obstetrics and Gynaecology, Mukherjee Multispecialty Hospital, Nagpur, Maharashtra, India.

\section{BACKGROUND} ABSTRACT

Urinary tract infection in pregnancy is one of the most common bacterial infections, which if not treated can cause serious harm to both mother and foetus. A woman is predisposed to urinary tract infection because of the close proximity to vagina and anus, in addition to low immunity during pregnancy. Timely intervention in the form of appropriate screening and treatment can reduce the morbidity. This review discusses the underlying pathophysiology of urinary tract infection in pregnancy and clinical guidelines regarding the use of different medications for prevention and treatment of urinary tract infection in pregnancy.

\section{KEY WORDS}

Urinary Tract Infection, Nitrofurantoin, Bacteriuria.

HOW TO CITE THIS ARTICLE: Mukherjee A, Mukherjee A. Urinary tract infection in pregnancy. J. Evolution Med. Dent. Sci. 2018;7(39):4313-4317, DOI: 10.14260/jemds/2018/961

\section{BACKGROUND}

- It is the most common bacterial infection during pregnancy.

- Incidence is around $8 \%$ in pregnancy.

\section{Types of Urinary Tract Infections}

1. Uncomplicated UTI: When infection occurs in a patient without any functional and anatomic abnormality or instrumentation of the urinary tract is called Uc-UTI.

2. Complicated UTIs: When infection occurs in a patient with abnormal urinary tracts with stones or associated disease, e.g. DM or others is called CUTI.

3. Recurrent UTIs: Repeated episodes of UTIs either complicated or uncomplicated.

4. Catheter: Associated UTIs (CAUTI).

5. According to Location: Upper UTI (Kidneys and Ureters) and Lower UTI (Urinary bladder, Prostate and Urethra).

- Upper UTIs- Pyelonephritis can be a life-threatening illness, as it is associated with increased risk of perinatal and neonatal morbidity.

- Recurrence of UTI is very common and requires prophylactic treatment.

\section{Risk Factors for UTI in Non-Pregnant Women}

- The anatomical factor- Shorter length of urethra in female and close proximity to anus and thereby risk of faecal - perineal - urethral contamination.

- There is altered vaginal flora in case of genitourinary infections. The usual dominant bacteria of vagina is lactobacilli, which helps to maintain the acidic $\mathrm{pH}$ of vagina.

'Financial or Other Competing Interest': None.

Submission 18-08-2018, Peer Review 12-09-2018,

Acceptance 18-09-2018, Published 24-09-2018.

Corresponding Author:

Dr. Alka Mukherjee,

Mukherjee Multispeciality Hospital,

\#179, Ayurvedic Layout, Bhande Plot Sq.,

Sakkaradara, Nagpur-440024,

Maharashtra, India

E-mail: mukherjeehospital@yahoo.com apurvam1795@gmail.com

DOI: $10.14260 /$ jemds $/ 2018 / 961$

\section{(c) $(1) \$$}

- Low immunity also plays an important role.

- In patients suffering from Diabetes Type 1, patients suffer from asymptomatic bacteriuria if they have longstanding DM in addition to peripheral neuropathy and microalbuminuria, which gets on and off reactivated in case of low immunity.

- In patients having Type $2 \mathrm{DM}$. there is a history of recent symptomatic UTI and neuropathy involving the urinary tract in addition to dysfunctional voiding and urinary retention. These patients are usually of higher age and they also have microalbuminuria.

- If patient is suffering from dysfunctional voiding, she is prone for recurrent UTIs.

- Patients having problems like voluntary withholding of urine, detrusor instability, dyssynergistic sphincter, there is disruption in laminar urine flow and bacteria get transferred back from the meatus to the bladder (Milk Back Phenomenon), they also have recurrent UTIs.

\section{Why Pregnant Women are at Increased Risk for Urinary} Tract Infection(1,2)

In addition to the above risk factors for UTI in women in general there are anatomical and physiological changes in pregnancy which makes the pregnant women more prone for UTI, especially upper urinary infection-

- The kidneys become larger, there is dilatation of the renal calyces and ureter.

- In pregnancy from 6 weeks to 22 - 24 weeks (peak), almost $90 \%$ women develop ureteral dilatation because of progesterone-induced relaxation of the muscular layers, which remain until delivery. More marked dilatation is apparent beginning in mid-pregnancy, because of ureteral compression, especially on the right side (Faundes and associates, 1998). Then there is increased bladder volume, increased urinary stasis, decreased bladder tone, decreased ureteral tone which leads to development of ureterovesical reflux which increases chances of UTI.

- $\quad$ Evidence of functional hypertrophy becomes apparent very soon after conception. Glomeruli are larger (though cell numbers do not increase) (Strevens and colleagues, 2003). Pregnancy induced intrarenal vasodilatation increases effective renal plasma flow and glomerular 
filtration. By 12 weeks gestation, the GFR is already increased $20 \%$ above non-pregnant values (Hladunewich and colleagues, 2004). Ultimately, plasma flow and GFR increased by 40 and $65 \%$ respectively.

- Serum concentrations of creatinine and urea decreased substantially across the pregnancy.

- There are chances of catheterisation either in intra or postpartum period, which again carry an increased risk of UTI.

- The co-morbid conditions like Diabetes Mellitus(Cousins 1987) observed that antepartum pyelonephritis developed in $4 \%$ of women with Type 1 diabetes compared with $1 \%$ those without diabetes.

- $\quad$ Sickle cell trait and disease, both pose additional threat of UTI. There is two-fold increased incidence of asymptomatic bacteriuria and urinary infection.

- Overall immunity during pregnancy is low and hence pregnant patient tend to face more severe sequelae of UTI.

\section{Causative Organisms: Bacteriology}

a. Most common organisms are same in pregnancy and non-pregnant women and they are Escherichia coli in $80-90 \%$ cases.

b. Gram negative rods- Proteus mirabilis and Klebsiella pneumoniae (Common).

c. Gram positive- Group B Streptococci and Staphylococcus saprophyticus (Less Common).

d. Enterococci.

e. Gardnerella vaginalis.

f. Ureaplasma urealyticum.

\section{Investigations}

1. Urine routine and culture sensitivity of urine. Specimen collection is the most important and crucial prerequisite and it should be a proper method with minimal contamination. The most optimal method is collection of mid-stream urine by spreading the labia. Routine catheterisation for sample collection should never be advised, as it is hazardous for risk of introducing infection. Likewise, same applies for specimen handling and processing. It is to be done in a proper way in order to avoid false positive results.

2. Blood cultures may be required in case of suspected pyelonephritis with s/o sepsis or in case of diabetes mellitus.

3. USG if there is suspicion of renal stones or DM or $\mathrm{H} / \mathrm{O}$ prior urologic surgery or patient on immunosuppressants or repeated episodes of pyelonephritis and urosepsis. In all these conditions renal USG is the preferred modality in pregnancy.

\section{Differential Diagnoses}

1. Intra-amniotic infection.

2. Preterm labour.

3. Placental abruption.

\section{Acute Urethritis or Acute Urethral Syndrome(3)}

Usually caused by one of the three organisms: Coliforms, (Principally E. coli), N. gonorrhoeae and C. trachomatis. Coliform organisms are part of normal vaginal and perineal flora and may be introduced into the urethra during intercourse or when wiping after defecation. N. gonorrhoeae and C. trachomatis are sexually transmitted pathogens.

\section{Signs and Symptoms}

Patients typically experienced frequency, urgency and dysuria. Hesitancy, dribbling and a mucopurulent urethral discharge also may be present.

\section{Investigations}

1. Urine Microscopy- Usually WBC are present, but bacteria may not be present.

2. Urine Culture- Low colony counts of coliform organisms.

3. Culture of urethral discharge may be positive for gonorrhoea and chlamydia. A rapid diagnostic test such as NAAT, is now the preferred method for identification of gonorrhoea and chlamydia.

\section{Treatment}

1. Most of the times, these patients are started with empiric treatment before the results of laboratory tests are available.

2. Coliform bacteria- nitrofurantoin monohydrate, fosfomycin and cephalexin are the drugs of choice.

3. Gonococcal infection- Intramuscular Ceftriaxone $250 \mathrm{mg}$ in a single dose) plus $1000 \mathrm{mg}$ oral azithromycin or azithromycin $2000 \mathrm{mg}$ orally in a single dose (precautions to be taken for gastrointestinal side effects).

4. Chlamydial infection- Azithromycin $1000 \mathrm{mg}$ in a single dose.

\section{Asymptomatic Bacteriuria}

Significant bacteriuria may exist in asymptomatic patients.

\section{Prevalence in Pregnancy}

$2-10 \%,(4,5)$ therefore routine screening in pregnancy is advised.

\section{Definition}

Two consecutive voided urine specimens with isolation of the same bacterial strain in quantitative counts of $\geq 10^{\wedge} 5$ colony forming units (cfu) $/ \mathrm{mL}$ or a single catheterised urine sample with one bacterial species isolated in a quantitative count of $\geq 10^{\wedge} 2 \mathrm{cfu} / \mathrm{mL}$ in asymptomatic women.(6,7) In clinical practice, usually one voided urine specimen is typically obtained.

\section{Follow-Up}

Due to upto $30 \%$ chance of persistence of infection; follow-up culture is done one week after the antibiotics course and monthly cultures are preferred throughout pregnancy due to the risk of persistence of infection or recurrence.(7)

\section{Investigations}

a) Urine culture at 12 - 16 weeks/ $1^{\text {st }} \mathrm{ANC}$ visit.

b) If initial test negative- rescreening not done in low risk patients.

c) High risk patients- H/O UTI, Urinary tract anomalies, DM, Haemoglobin S or preterm labour- Rescreening must. 
Complications because of Asymptomatic Bacteriuria in Pregnancy are as Follows-

\section{Maternal Complication}

Hypertension

Pre-eclampsia

: Intrauterine growth retardation

Anaemia

: Intrauterine death

Symptomatic acute cystitis : Prematurity

Acute pyelonephritis $\quad$ : Low birth weight

\section{Recurrent Bacteriuria}

It is defined as when the $1^{\text {st }}$ follow-up culture is positive with a different species or if a subsequent culture is positive with the same or different species requires antibiotic treatment as per susceptibility and organisms detected. However, available data does not support antibiotic prophylaxis for recurrent asymptomatic bacteriuria.(7)

\section{Screening as per ACOG Recommendation}

We should advice urine culture at $1^{\text {st }}$ prenatal visit and then repeat urine culture during $3^{\text {rd }}$ trimester (As urine of treated patients may not remain sterile for the entire pregnancy).

\section{Clinical Symptoms of UTI depends on the Types of UTI a} Patient is having like-

- Types of UTI

Typical Symptoms and Signs.

- Cystitis

Frequent voiding, suprapubic pain, burning micturition, Haematuria, cloudy urine.

\section{- Pyelonephritis}

Fever chills, flank pains, N/Vomiting, Cystitis $\mathrm{Sx} \pm$

- Urosepsis

Fever - Chills, Shock.

\section{Acute Cystitis: Incidence is 1 - 2\%}

Acute cystitis is to be distinguished from asymptomatic bacteriuria by the presence of symptoms like sudden-onset dysuria, urgency and frequency where the patients are afebrile and there is no evidence of systemic illness. It is seen that $30 \%$ of untreated asymptomatic bacteriuria patients later developed symptomatic cystitis. Diagnosis is by urinalysis, wherein usually there is a picture of haematuria and pyuria.

\section{Treatment of Acute Cystitis(7)}

Generally, treatment of pregnant patients with acute cystitis is initiated empirically before the results of the culture. Preferably, regarding, choice of antibiotic one should try to focus on coverage of common pathogens and can be changed once the organism is identified. Different antibiotic regimens have similar efficacy and complications are rare. A 3 to 7 days course of antibiotics is given in the absence of symptoms of pyelonephritis. Available data shows no difference between short and long antibiotic courses. ${ }^{(8)}$

\begin{tabular}{|c|c|c|}
\hline Antibiotic & $\begin{array}{c}\text { Pregnancy } \\
\text { Category }\end{array}$ & Dosage \\
\hline Fosfomycin & B & One 3 gm sachet - single dose \\
\hline Cephalexin & B & $\begin{array}{c}250 \mathrm{mg} \text { bid/qid daily for 3 to 7 } \\
\text { days }\end{array}$ \\
\hline Erythromycin & B & $\begin{array}{c}250-500 \text { mg qid daily for 3 to 5 } \\
\text { days }\end{array}$ \\
\hline
\end{tabular}

\begin{tabular}{|c|c|c|}
\hline Nitrofurantoin & B & $\begin{array}{c}100 \mathrm{mg} \text { qid daily for } 5 \text { to } 7 \\
\text { days }\end{array}$ \\
\hline $\begin{array}{c}\text { Amoxicillin and } \\
\text { clavulanic acid }\end{array}$ & B & $\begin{array}{c}500 \mathrm{mg} \text { tds daily for } 3 \text { to } 7 \\
\text { days }\end{array}$ \\
\hline $\begin{array}{c}\text { Trimethoprim - } \\
\text { sulfamethoxazole }\end{array}$ & C & $\begin{array}{c}160 / 180 \text { mg bid daily for } 3 \\
\text { days }\end{array}$ \\
\hline \multicolumn{2}{|c|}{ Table 1. Treatment of Acute Cystitis(9,10) } \\
\hline
\end{tabular}

Few important points to remember like short courses of antimicrobial therapy can be considered, but there can be a high recurrence rate with serious consequences. Among the antibiotics Penicillins, Cephalosporins or Fosfomycin can be considered. The drug Nitrofurantoin even though safe, cannot be given in G6P deficiency and at the end of pregnancy for the risk of haemolytic anaemia in newborn. Trimethoprim and sulphonamides not in $1^{\text {st }}$ trimester as there is a risk of congenital malformations. Sulphonamides are also avoided immediately prior to delivery, because of concern about displacement of bilirubin from protein binding sites resulting in neonatal jaundice.(3) Therapy should be $3-7$ days course and follow-up as in asymptomatic bacteriuria.

\section{Recurrent Cystitis}

In addition to the antibiotic treatment, antimicrobial prophylaxis throughout the duration of pregnancy is preferred. Prophylaxis can be continuous or postcoital depending on how the patient presents. The preferred drug and doses are 50 - $100 \mathrm{mg}$ Nitrofurantoin/ $250-500 \mathrm{mg}$ Cephalexin HS daily.

\section{Pyelonephritis}

It is a serious systemic illness during pregnancy with an incidence of 0.5 - $2 \%$ of pregnant women,(11,12,7) (Upto $23 \%$ of these pregnant women have a recurrence during the same pregnancy). Pyuria is a typical finding. Most cases of pyelonephritis occur during the second and third trimesters. Pregnant women may become quite ill and are at risk for both medical and obstetrical complications from pyelonephritis. As many as 20 percent of women with severe pyelonephritis develop complications that include septic shock syndrome or its variants such as acute respiratory distress syndrome.

\begin{tabular}{|c|c|}
\hline Category & Finding \\
\hline History & $\begin{array}{c}\text { Lower urinary tract symptoms (e.g. } \\
\text { frequency, urgency, dysuria), Upper } \\
\text { urinary tract symptoms (e.g. flank pain), } \\
\text { constitutional symptoms (e.g. nausea, } \\
\text { vomiting, anorexia, abdominal pain). }\end{array}$ \\
\hline $\begin{array}{c}\text { Physical } \\
\text { examination }\end{array}$ & $\begin{array}{c}\text { tachycardia, hypotension, } \\
\text { costovertebral angle tenderness, } \\
\text { possible abdominal or suprapubic } \\
\text { tenderness. }\end{array}$ \\
\hline Laboratory tests & $\begin{array}{c}\text { Urinalysis showing positive leukocyte } \\
\text { esterase test, microscopic pyuria or } \\
\text { haematuria or white blood cell cases. } \\
\text { Peripheral blood smear showing } \\
\text { leukocytosis with or without left shift. } \\
\text { Positive blood culture in 15 to 30 } \\
\text { percent of cases. Urine culture growing } \\
\geq 10 \text { colony forming units per mL of } \\
\text { urine }\end{array}$ \\
\hline \multicolumn{2}{|c|}{ Acute Pyelonephritis } \\
\hline
\end{tabular}




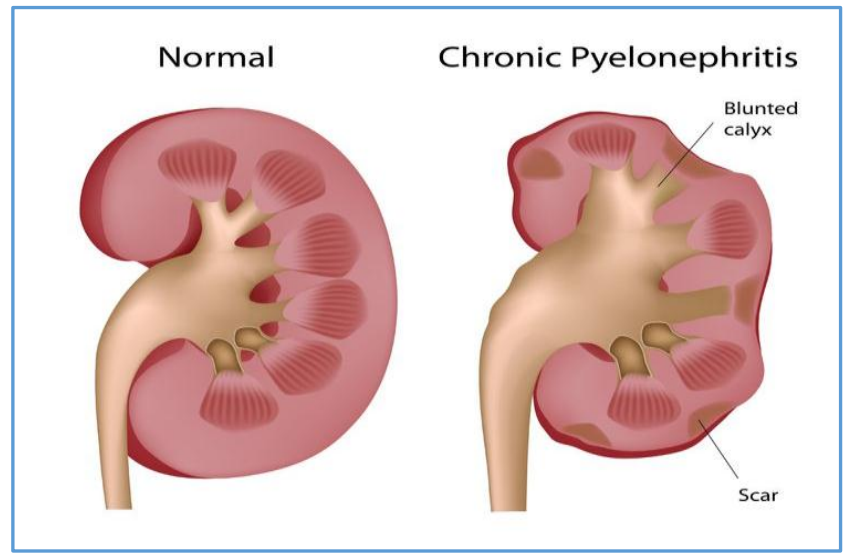

Diagram 1. Chronic Pyelonephritis

\section{Diagnosis (By Other Modalities)}

Severe cases patients might need a renal ultrasonography or may be an abbreviated intravenous pyelogram. IV pyelogram is indicated in persistent infection after appropriate antibiotic therapy when there is a suspicion of structural abnormality, which is not seen on USG. But the low dose radiation involved can be dangerous to foetus, so long as one should try to avoid.

\section{Maternal Complications of Pyelonephritis}

a) Anaemia- due to haemolysis mediated by endotoxin.

b) Sepsis- $20 \%$ of severe pyelonephritis can land up in sepsis.

c) Respiratory distress and ARDS- Due to endotoxin induced lung injury.

d) Acute renal failure- because of microabscesses.

e) Suppurative pyelonephritis.

\section{Foetal Complications}

a) Increased risk of preterm birth.

b) Low birth weight

c) Perinatal mortality.

\section{Treatment of Pyelonephritis(2)}

Patient should be treated aggressively, which is important for preventing complications. Fluoroquinolones and aminoglycosides should be avoided in pregnancy, if possible. Otherwise, they are very effective for pyelonephritis in nonpregnant individuals. (7)

- Hospitalisation is a must if signs of sepsis, dehydration, vomiting or patient started having uterine contractions, preterm labour, or complication of pyelonephritis.

- Obtain urine and blood culture.

- Evaluate haemogram, serum creatinine and electrolytes.

- Monitor vital signs frequently including urine outputcatheterise patient if necessary.

- Antibiotics may be initiated before obtaining the result of urine culture and sensitivity.

- Start hydrating the patient with IV fluids. Establish urine output $\geq 50 \mathrm{~mL}$ per hour with intravenous crystalloids.

- Obtain chest radiograph if there is dyspnoea or tachypnoea.

- $\quad$ Parental treatment should be continued till the patient is afebrile. Most respond in 24 - 48 hours, then change to oral antibiotic for 7 to 10 days.
- If initial treatment failure is there, that can be because of resistance to antibiotic. If fever persists, then suspect either structural or anatomic abnormality and investigate further. Persistent infection can be seen in urolithiasis (1 in 1500 pregnancies) or congenital renal abnormality or perinephric abscess.

- Discharge when afebrile for 24 hours with oral antibiotics for 7 to 10 days.

- Repeat urine culture 1 - 2 weeks after antimicrobial therapy completed.

\begin{tabular}{|c|c|}
\hline Antibiotic & Dose, Interval \\
\hline \multicolumn{2}{|l|}{ Mild-to-moderate PN } \\
\hline Ceftriaxone & 1 - 2 gms every 6 hourly \\
\hline Cefepime & 1 gm every 12 hours \\
\hline Aztreonam & 1 gm every 8 hours \\
\hline Ampicillin with gentamicin & $\begin{array}{c}1 \text { - } 2 \text { gm every } 6 \text { hours / } 1.5 \\
\text { mg/kg every } 8 \text { hours }\end{array}$ \\
\hline Severe PN with an impaired & and/or incomplete urinary \\
\hline $\begin{array}{c}\text { immunity } \\
\text { Pineracillin-taztam }\end{array}$ & $\begin{array}{c}\text { tract obstruction } \\
\end{array}$ \\
\hline Meropenem & 1 gm every 8 hours \\
\hline Ertapenem & 1 gm every 24 hours \\
\hline Doripenem & 500 every 8 hours \\
\hline
\end{tabular}

- Oral antibiotic therapy should be switched over to oral therapy if patient is afebrile for 48 hours, that too for 10 14 days. Beta lactams or trimethoprim-sulfamethoxazole are the preferred oral antibiotics in $2^{\text {nd }}$ trimester. The drugs like Nitrofurantoin and Fosfomycin are not appropriate in pyelonephritis, as there are inadequate tissue levels. If patient continues to have persistent signs and symptoms beyond first 24-48 hrs., one should do repeat urine culture and renal USG to rule out persistent infection and urinary tract pathology.

- Regarding timing of delivery, one should wait till patient is afebrile and relative foetomaternal safety is ensured. Delivery is only for obstetric reasons. In case of preterm labour, tocolysis required before 34 weeks in uncomplicated Pyelonephritis with preterm labour. In those cases along with tocolysis, foetal lung maturity should be achieved with corticosteroid injections. There is no role of tocolysis if patient is in sepsis as increased risk of pulmonary oedema and ARDS.

- OPD treatment of Pyelonephritis should be discouraged. In case of recurrent Pyelonephritis, low dose antibiotics as in acute cystitis should be given for rest of pregnancy.

\section{UTI because of Group B Streptococcal Infection (GBS Infection)}

Group B Streptococcal vaginal colonisation is the root cause for neonatal sepsis. It is associated with preterm rupture of membranes, pre-term labour and delivery. Incidence of GBS in pregnancy- 5\%. The evidence that GBS bacteriuria increases risk of premature rupture of membranes or preterm labour is mixed. An RCT report conducted showed that there is significant reduction in rates of PROM and preterm labour in women who received antibiotics. All pregnant women with GBS bacteriuria should be treated as GBS carriers and should receive a prophylactic antibiotic during labour. 


\section{Recurrence and Prophylaxis}

Incidence of recurrence of UTI is around $4-5 \%$ of the pregnancies and risk of developing pyelonephritis is the same as the risk with primary UTIs. Majority of UTIs are caused by gastrointestinal organisms. Even with appropriate treatment, reinfection can occur from rectal reservoir. A postpartum urologic evaluation may be necessary in patients with recurrent infections. They are more likely to have structural abnormalities of renal system. Patients with urinary stones or more than one recurrence or recurrence while on antibiotic should undergo postpartum evaluation.

Pregnancy and Recurrent UTI- Indications for Prophylaxis

- All women with a pre-pregnancy h/o recurrent UTIs are the candidates for prophylaxis. If there is persistent symptomatic patient or asymptomatic bacteriuria after two antibiotic treatments, they should be given prophylaxis. Pregnant patients with only one episode of UTI with other potential risk factors like DM and SCD should also receive prophylaxis.

- Drug of choice for prophylaxis is-

1. Nitrofurantoin $50 \mathrm{mg}$ daily (Avoided at 36 weeks).

2. Cephalexin $250 \mathrm{mg}$ daily.

\section{Outcomes}

It is observed that $30 \%$ patients with untreated asymptomatic bacteriuria tend to develop symptomatic cystitis, 50\% develop Pyelonephritis. Maternal and neonatal complications are usually devastating. It is seen that even asymptomatic bacteriuria is associated with IUGR and low birth weight infants.

\section{UTI can be associated with-}

1. Preterm labour.

2. HDP.

3. Anaemia.

4. Amnionitis.

UTI- The Most Common Bacterial Infection in Pregnancy; Antibiotics are Mainstay

To Sum Up

1. UTIs in pregnancy- common cause of serious maternal and perinatal morbidity- preterm birth, low birth weight and perinatal mortality.

2. Low immunity during pregnancy - more severe sequelae of UTI.

3. With appropriate screening and treatment- morbidity can be limited.

4. UTIs- can be of 3 types- asymptomatic bacteriuria, acute cystitis, Pyelonephritis.

5. All pregnant women should be screened and treated with antibiotics.
6. Acute cystitis and pyelonephritis need aggressive treatment.

7. Oral nitrofurantoin, fosfomycin and cephalexin are good antibiotic choices for asymptomatic bacteriuria and acute cystitis.

8. Pyelonephritis may require parenteral antibiotic therapy.

\section{REFERENCES}

[1] Mishra V. Urinary tract infection. FOGSI FOCUS, Published by FOGSI, MUMBAI, 2018.

[2] Cunningham FG, Leveno KJ, Bloom SL, et al. Williams Obstetrics. 23 ${ }^{\text {rd }}$ edn. McGraw-Hill Professional 2009: p. 1033-7.

[3] Gabbe SG, Niebyl JR, Sympson JL, et al. Obstetrics: normal and problem pregnancies. 7 th edn. Elsevier 2016: p. 850-3.

[4] Smaill FM, Vazquez JC. Antibiotics for asymptomatic bacteriuria in pregnancy. Cohrane Database Cyst Rev 2015;(8): CD000490.

[5] Widmer M, Lopez I, Gulmezoglu AM, et al. Duration of treatment for asymptomatic bacteriuria during pregnancy. Cochrane Database Syst Rev 2015;(11):CD000491.

[6] Nicolle LE, Bradley S, Colgan R, et al. Infectious Diseases Society of America guidelines for the diagnosis and treatment of asymptomatic bacteriuria in adults. Clin Infect Dis 2005;40(5):643-54.

[7] Pal B, Wani R, Goswami S. Infections in obstetrics and gyanecology checklist for management. FOGSI FOCUS, Published by FOGSI, MUMBAI, 2017: p. 27-30.

[8] Gupta K, Hooton TM, Naber KG, et al. International clinical practice guidelines for the treatment of acute uncomplicated cystitis and pyelonephritis in women: A 2010 update by the Infectious Disease Society of America and the European Society for Microbiology and Infectious Diseases. Clin Infect Dis 2011;52(5):e103-20.

[9] Cunningham FG, Lucas MJ. Urinary tract infections complicating pregnancy. Baillieres Clin Obstet Gyanaecol 1994;8(2):353-73.

[10] Schneeberger C, van den Heuvel ER, Erwich JJ, et al. Contamination rates of three urine-sampling methods to assess bacteriuria in pregnant women. Obstet Gyanecol 2013;121(2 Pt 1):299-305.

[11] Gilstrap LC 3 ${ }^{\text {rd }}$, Ramin SM. Urinary tract infections during pregnancy. Obstet Gyanecol Clin North Am 2001;28(3):581-91.

[12] Wing DA, Fassett MJ, Getahum D. Acute pyelonephritis in pregnancy: an 18-year retrospective analysis. Am J Obstet Gyanecol 2014;210(3):219.e1-e6. 